Setting the threshold for surgical prevention in women at increased risk of ovarian cancer

*Ranjit Manchanda ${ }^{1,2,3}$, Usha Menon ${ }^{3}$

${ }^{1}$ Barts Cancer Institute, Queen Mary University of London, Old Anatomy Building, Charterhouse Square, London, EC1M 6BQ, UK

${ }^{2}$ Department of Gynaecological Oncology, St Bartholomew's Hospital, London, UK, EC1A 7BE

${ }^{3}$ Gynaecological Cancer Research Centre, Department of Women's Cancer, Institute for Women's Health, University College London, 149 Tottenham Court Road, London, UK, W1T 7DN.

*Correspondence to:

Dr Ranjit Manchanda

Barts Cancer Institute, Queen Mary University of London,

Old Anatomy Building, Charterhouse Square, London, EC1M 6BQ, UK

Email: r.manchanda@qmul.ac.uk 


\section{Setting the threshold for surgical prevention in women at increased risk of ovarian cancer}

\section{Abstract}

The number of ovarian cancer cases is predicted to rise by $14 \%$ in Europe and $55 \%$ worldwide over the next two decades. The current absence of a screening programme, rising drug/treatment costs, and only marginal improvements in survival seen over the last 30 years, suggests the need for maximising primary surgical prevention to reduce the burden of ovarian cancer. Primary surgical prevention through risk-reducing salpingo-oophorectomy (RRSO) is well established as the most effective method for preventing ovarian cancer. In the UK it has traditionally been offered to high risk women (>10\% lifetime risk of ovarian cancer) who have completed their family. The costeffectiveness of RRSO in BRCA1/BRCA2 carriers $>35$ years is well established. Recently RRSO has been shown to be cost-effective in post-menopausal women at lifetime ovarian cancer risks $\geq 5 \%$ and in premenopausal women at lifetime risks $>4 \%$. The acceptability, uptake and satisfaction with RRSO at these intermediate-risk levels remain to be established. Prospective outcome data on riskreducing salpingectomy and delayed-oophorectomy for preventing ovarian cancer is lacking and hence, this is best offered for primary prevention within the context and safe environment of a clinical trial. An estimated $63 \%$ of ovarian cancers occur in women with $>4 \%$ lifetime-risk and $53 \%$ in those with $\geq 5 \%$ lifetime-risk. RRSO can be offered for primary surgical prevention to women at intermediate risk levels (4-5\% to $10 \%)$. This includes unaffected women who have completed their family and have RAD51C, RAD51D or BRIP1 gene mutations; first-degree relatives of women with invasive epithelial ovarian cancer; BRCA negative women from high-risk breast- $\&$-ovarian cancer or ovarian cancer only families. In those with $B R C A 1, R A D 51 C / R A D 51 D / M M R$ mutations and the ocassional families with history of ovarian cancer in their 40 s surgery needs to be considered at $<45$. In other moderate risk gene mutation carriers and those with polygenic risk, RRSO needs be considered at 50. There is need for establishment/expansion of well-defined pathways to increase clinical access to RRSO. It is time to lower the risk threshold for RRSO to enable introduction of a 
targeted primary prevention approach which could significantly impact the future burden of ovarian cancer.

Key Words: Ovarian Cancer, prevention, risk threshold, surgical prevention, salpingectomy, salpingooophorectomy 


\section{Setting the threshold for surgical prevention in women at increased risk of ovarian cancer}

The GLOBOCAN project of the International Agency for Research on Cancer (IARC) predicts that by 2035 the number of cases of ovarian cancer will rise by $14 \%$ in Europe and $55 \%$ worldwide. It also estimates that the number of deaths from ovarian cancer will rise by $22 \%$ in Europe and by $67 \%$ worldwide over the same time. ${ }^{1}$ Advances in treatment strategies have resulted in only a small impact on survival over the last three decades. ${ }^{2}$ Both in the low risk UK Collaborative Trial of Ovarian Cancer Screening (UKCTOCS). ${ }^{3}$ and the high risk women United Kingdom Familial Ovarian Cancer Screening Study (UKFOCSS) a CA125 based multimodal screening strategy has shown promise with significantly more women being diagnosed with earlier stage disease and lower tumour volume during screening. ${ }^{4}$ However in UKCTOCS there is as yet no conclusive mortality benefit. Hence unlike in breast or cervical cancer, screening programmes for ovarian cancer are not recommended. Even if a mortality benefit were proven on extended follow-up in UKCTOCS, ${ }^{5}$ primary prevention strategies remain the most proven method in reducing population burden of disease, with immunisation being a prime example. In ovarian cancer this translates into primary surgical prevention. Given the minimal impact observed with alternative strategies, and rising drug/treatment costs, maximising primary surgical prevention needs to be at the core of our efforts to reduce the burden of ovarian cancer in the future. This approach fits well with recent strategic initiatives which emphasise the need for greater focus on cancer prevention, such as the Independent Cancer Task Force, Cancer Strategy for England 2015-2020, ${ }^{6}$ and the Obama Precision Medicine initiative. ${ }^{7}$

In the general population, the life time risk of ovarian cancer ranges from $1.3 \%$ to $2 \%^{8,9} \mathrm{In}$ BRCA1/BRCA2 mutation carriers lifetime ovarian cancer risks range from $17 \%-44 \%$ and worldwide these women are considered to be at high risk. ${ }^{10-12}$ Historically, restricted access to $B R C A$ testing in many countries (including the UK) led to women being classified on the basis of family history alone. In the UK we have historically defined women as being high risk if they are estimated to have a life 
time risk of ovarian cancer of $\geq 10 \% .{ }^{4,13}$ This was the clinical threshold for screening and prevention used within the national UKFOCSS trial and followed in many high-risk clinics. ${ }^{4,14,15}$ This corresponded to the average estimate of ovarian cancer risk in untested women from high risk families. However, there was no well-defined scientific basis for this clinical convention. To the best of our knowledge, there are no 'peer reviewed' 'published' clinical guidelines anywhere which previously defined the ovarian cancer risk threshold for surgical prevention.

In more recent years, high throughput next generation sequencing technologies and advances in computational bioinformatics have heralded significant change in this genomic landscape. Firstly cheaper testing has led to many of the restrictions around $B R C A$ testing to be removed. In the UK, for example since 2016, women who have never had cancer and are considered to be at a $10 \%$ risk of carrying the BRCA gene mutation are being offered testing. Secondly, a number of new moderate penetrance ovarian cancer gene mutations have been identified, such as RAD51C (lifetime ovarian cancer risk $=11.2 \%, \mathrm{Cl}:(5.7 \%, 21.3 \%)),{ }^{16} \operatorname{RAD} 51 D$ (lifetime ovarian cancer risk $=11.9 \%, \mathrm{Cl}:(5.7 \%$, $24.6 \%)^{17}$ and BRIP1 (lifetime ovarian cancer risk $=5.8 \%, \mathrm{Cl}:(3.65 \%, 9.1 \%) \cdot{ }^{18}$ Confidence intervals of these estimates will narrow as more data accrue. Unlike $B R C A 1 / B R C A 2$, mutations in these three moderate risk genes are not associated with an increased risk of breast cancer. Panel genetic testing for RAD51C, RAD51D and BRIP1 mutations (along with the traditional BRCA1/BRCA2 genes) is now available in clinical practice. Additionally a number of common genetic variants or Single Nucleotide Polymorphisms (SNPs) which impact ovarian cancer risk have been identified through genome wide association studies (GWAS). ${ }^{19,} 20$ While, the level of risk associated with each individual SNP is small (odds ratios range from 0.8 to 1.4 ), a combination of SNPs present together could have a multiplicative effect on risk in a single individual. The impact of the SNP profile is estimated through a polygenic risk score. This SNP profile/ polygenic risk score coupled with epidemiological variables (e.g. parity, age, endometriosis, tubal ligation, first degree relative with ovarian cancer, contraceptive pill use and BMI) have been incorporated into recently published risk models 
developed by consortia like OCAC (Ovarian Cancer Action Consortium). These can predict ovarian cancer risk on a wider population basis. ${ }^{21,} 22$ Additionally, further model development work is being undertaken within OCAC and by others. A similar strategy is also being employed by large groups like CIMBA (Consortium of Investigators of Modifiers of $B R C A 1 / 2$ ) to further improve the precision of risk estimates and enable stratification in high risk women such as $B R C A 1 / B R C A 2$ carriers. BRCA1/BRCA2 mutations are responsible for only $1 / 4^{\text {th }}$ of the familial relative risk for ovarian cancer. A SNP based polygenic risk driven strategy has been shown to improve risk prediction in BRCA negative women with a strong family history of cancer. ${ }^{11}$ Ovarian cancer risk models incorporating epidemiologic factors, high penetrance genes, moderate penetrance genes and common genetic variants are also being developed and validated in the PROMISE (Predicting Risk of Ovarian Malignancy Improved Screening and Early detection) programme. ${ }^{23}$ Thus our ability to identify women at varying intermediate ranges of ovarian cancer risk has been significantly boosted. As more sophisticated models are developed and get validated over the coming years, clinical applicability will improve.

In addition to lifetime risk, a critical factor is the age when risk begins to rise. For $B R C A 1$ the risk begins to rise at 35 years ( $2 \%$ below age 40 rising to $5 \%$ if 2 or more first degree relatives with OC) ${ }^{12}$ but becomes more significant after the age of 40 years. For $B R C A 2$ this risk does not begin to rise before 40 years and becomes more significant after the age of 45 years. Hence, RRSO doesn't need to be undertaken before $35-40$ years in BRCA1 and can be delayed till $40-45$ years in BRCA2 carriers. Ovarian cancers not linked to pathogenic mutations are more likely to present after the menopause, with risks beginning to rise after 50 years age. Decision making on whether to undergo RRSO 'or not' is a complex and dynamic process which changes with time. ${ }^{15}$ It can be affected by the age of the person, the history of cancer in self or family, presence of a gene mutation, the risks associated with premature menopause and personal preference.

\section{Risk reducing salpingo-oophorectomy (RRSO)}


Primary surgical prevention through removal of both tubes and ovaries is well established as the most effective method for preventing ovarian cancer. It is routinely offered to high risk women who have completed their family with uptake rates of up to $70 \%$, satisfaction rates of up to $97 \%$ and regret rates of $\sim 5 \% .{ }^{15,24} B R C A 1 / B R C A 2$ carriers undergoing this procedure benefit from a $80 \%$ reduction in ovarian cancer risk, ${ }^{25} \sim 79 \%$ reduction in ovarian cancer specific mortality ${ }^{26}$ and $\sim 60 \%$ reduction in all-cause mortality. ${ }^{26} \mathrm{~A} 2-4 \%$ post-surgical risk of primary peritoneal cancer (PPC) has been reported over 20 years. Average risk women undergoing bilateral salpingo-oophorectomy can also benefit from a $~ 94 \%$ reduction in ovarian cancer risk. ${ }^{27}$ This raises the issue of the ovarian cancer risk threshold at which primary surgical prevention should be offered more widely. While cost-effectiveness of RRSO in BRCA1/BRCA2 carriers who are over 35 and have completed their families is well established ${ }^{28}$ the cost-effectiveness at lower levels of risk was only recently reported. We developed decision analytic models to identify the ovarian cancer risk thresholds which would be appropriate for RRSO based primary surgical prevention in both pre-menopausal ${ }^{29}$ and postmenopausa| ${ }^{30}$ women. Decision modelling provides a logical, quantitative and transparent framework for evaluating costs and consequences (health outcomes) which result from a sequence of events following alternative treatment strategies. Cost-effectiveness analysis has been highlighted by the National Institute of Health and Care Excellence (NICE) as the favoured form of economic assessment to compare relative costs and health outcomes in decision modelling. ${ }^{31}$ The model outcome is described in terms of an incremental cost-effectiveness ratio (ICER) / quality adjusted life-year (QALY). This is compared with the standard NICE thresholds for cost-effectiveness of $£ 20,000-30,000 / Q A L Y$. We found RRSO undertaken at $>50$ years to be cost-effective in postmenopausal women at a lifetime ovarian cancer risk of $\geq 5 \%$ (ICER $=£ 15247 / \mathrm{QALY})$. In premenopausal women undergoing RRSO at $>40$ years, the lifetime ovarian cancer risk threshold for RRSO was $>4 \%$ (ICER $=£ 19536 /$ QALY). The modelling incorporates a detriment for excess deaths from coronary heart/cardiovascular disease reported in the literature. ${ }^{27}$ The gains in life expectancy were found to be $>42.7$ days in premenopausal and $>29.2$ days in post-menopausal women. These 
levels are comparable to life expectancy gains of 11.6-32.4 days reported from other beneficial interventions such as cervical cancer screening. ${ }^{32}$ It is important to highlight that these life gains are averaged across the entire population and therefore, for an individual woman in whom an ovarian cancer is prevented, this figure is multiple times higher.

In premenopausal women, surgical menopause is associated with a detrimental impact on cardiovascular disease, sexual function, bone health, vasomotor symptoms and has potential neurological consequences. These side effects are predominantly seen in women who undergo RRSO under 45 years who are not on HRT ${ }^{27}$ Hence two issues are critical - one is age at RRSO in premenopausal women and the second is compliance with HRT use post surgery. It is only in those with $B R C A 1, R A D 51 C / R A D 51 D$ mutations and the ocassional families with history of ovarian cancer in their 40 s that surgery needs to be considered below the age of 45 . In other moderate risk gene mutation carriers and those with polygenic risk, RRSO needs be considered at 50. More detailed recommendations are listed in Table-1. Short-term HRT in women undergoing premature surgical menopause has not been shown to increase the risk of breast cancer..$^{33}$ In premenopausal women who cannot take HRT, the lifetime ovarian cancer risk threshold for cost-effectiveness of RRSO at $>40$ years is higher at $8.2 \%{ }^{29}$

\section{Risk Reducing Salpingectomy (RRS)}

There is increasing acceptance of a central role for the tube in the etiopathogenesis of ovarian cancer. Serous tubal intraepithelial carcinoma (STIC) is established as a precursor lesion, present as a continuum with early tubal carcinomas, supporting transition from insitu to invasive cancer. This coupled with the detrimental consequences of premature surgical menopause from RRSO has led to the attractive proposition of premenopausal early salpingectomy and delayed oophorectomy (postmenopausal) as a two-step approach for ovarian cancer prevention in high risk women. This has the advantage of providing reduction in ovarian cancer risk while avoiding the negative consequences of 
early menopause. As a result some centres have changed protocols. However, prospective data showing the benefit of risk reducing salpingectomy in this two stage approach are lacking. Two large retrospective analyses in low-risk women suggests that salpingectomy offers a $35 \%-42 \%$ reduction in OC-risk. ${ }^{34,35}$ However, these data are retrospective, suffer from indication and detection bias and number of OCs are few. A recent systematic review reconfirms the limited and low-quality of available evidence on level of OC-risk reduction and ovarian function. ${ }^{36}$ Additionally data from the low-risk population cannot be directly extrapolated to higher risk women. We have recently shown that fimbrial tissue can persist on the ovarian surface despite salpingectomy in $16 \%$ women. ${ }^{37}$ The precise level of reduction in risk obtained from salpingectomy alone especially in women at increased risk is not known. Additionally salpingectomy will not prevent cancers that arise outside the tube. While $70 \%$ occult insitu/invasive cancers discovered at histology in women undergoing RRSO are tubal in origin, $30 \%$ are not. ${ }^{38}$ Our understanding of the biology of STICs and the interplay of the tube and the ovary in the development of ovarian cancer is incomplete. Initial data from a recent genomic analysis indicates that in cases where STICs co-exist with invasive high grade serous ovarian cancer (HGSOC), STICs may be precursors of HGSOC in only $50 \%$ cases. $^{39}$ It has been suggested that a proportion of STICs may be metastatic to the tube and salpingectomy will not prevent ovarian cancer in these cases. ${ }^{40}$ The long term impact of RRS on ovarian function and onset of menopause is unknown. Although available short term data show no harmful impact on ovarian function, these studies have small sample sizes, use surrogate markers, and short duration of follow up. Short term hormonal function is not predictive of the final menstrual period or onset of menopause. ${ }^{41}$ Only longitudinal long term follow up data can address this question. A significant concern expressed by many is the attrition from delayed oophorectomy. It is possible some women may delay or not undergo post-menopausal oophorectomy and some may subsequently develop ovarian cancer. An additional gap in the literature is the lack of utility scores for salpingectomy. While one report in the literature suggests that a two-step approach could be cost-effective, ${ }^{42}$ the lack of prospective outcome data and various gaps in knowledge highlighted above preclude our 
ability to draw conclusions and maintains significant uncertainty around this issue. The precise risk thresholds for offering this in routine practice remain to be determined. Hence, risk reducing salpingectomy (RRS) and delayed oophorectomy is best offered for primary prevention within the context and safe environment of a clinical trial. There are currently three trials on going - in The Netherlands (TUBA study NCT02321228), ${ }^{43}$ The USA (MD Anderson study NCT01907789) and France (Radical Fimbriectomy study NCT01608074).$^{44}$ We found $~ 80 \%$ support amongst UK clinicians for such a study. ${ }^{45} \mathrm{~A}$ trial in the UK (PROTECTOR Study) is about to commence later this year.

\section{Changing the threshold for RRSO}

Data described above support offering RRSO for primary surgical prevention to women at intermediate levels of ovarian cancer risk, with lifetime risks ranging from $4-5 \%$ to $10 \%$. Table- 1 summarises recommendations for RRSO based on clinical picture and level of risk. Changing the threshold for RRSO to these levels could have significant impact on disease burden as an estimated $63 \%$ of ovarian cancers occur in women with $>4 \%$ lifetime risk and $53 \%$ in those with a $\geq 5 \%$ lifetime risk. ${ }^{11}$ Modelling suggests that $13 \%$ of the female UK population have a $>4 \%$ lifetime risk of ovarian cancer, while $9 \%$ has a $\geq 5 \%$ lifetime risk. ${ }^{11}$ Even without the new risk prediction models in clinical use, RRSO at these thresholds could immediately be offered to unaffected women who have completed their family and (a) have $R A D 51 C, R A D 51 D$ or BRIP1 gene mutations; (b) are first degree relatives of women with invasive epithelial ovarian cancer; or (c) are BRCA negative from high risk breast \& ovarian cancer (HBOC) families or high risk ovarian cancer ( $\mathrm{HOC}$ ) families without a known pathogenic mutation in the family. While for RAD51C/RAD51D carriers this would be advised after the age of 40 years, in BRIP1 carriers as ovarian cancers have not yet been reported below the age of 50 years. The timing of surgery could be delayed till 50 years in the bulk of the intermediate risk women, thus decreasing the impact of premature menopause. 
The acceptability, uptake and satisfaction with RRSO at these intermediate risk levels remain to be established. It is not known if the acceptability, uptake and satisfaction rates in intermediate risk women will be similar to the high levels found in high-risk women. The implementation of such an approach requires establishment or expansion of well-defined pathways to increase clinical access to RRSO. Additionally, it is critical for health professionals and women at risk to understand the importance of HRT following surgical menopause and to act on it to minimise/ ameliorate the potential detrimental long term health consequences. While HRT can ameliorate the negative side effects, it cannot completely alleviate all consequences (e.g. sexual dysfunction). These issues along with a $\sim 3 \%$ reported surgical complication rate must form part of the informed decision making process. Patients need to be properly and thoroughly counselled on the benefits, disadvantages and complications of surgery for surgical prevention. Appropriately designed and developed information sheets/decision making materials can help facilitate this. Structures also need to be put in place to safeguard continued availability of HRT prescriptions as well as to monitor compliance and long term health. This could have health service resource and capacity implications. Looking ahead, the development and validation of more complex, state of the art risk models will provide the opportunity to stratify women in the general population by their absolute lifetime risk of ovarian cancer. The feasibility of such an approach is being tested in an ongoing pilot study. ${ }^{23}$ Wider implementation of a targeted surgical prevention strategy for women at $>4-5 \%$ lifetime risk thresholds provides a huge opportunity for cost-effective targeted primary prevention. It is time for us to lower the risk threshold for RRSO to enable introduction of a primary prevention approach which could significantly impact the burden of ovarian cancer. 


\section{Disclosure of Interests}

UM has a financial interest in Abcodia, Ltd, a company formed to develop academic and commercial development of biomarkers for screening and risk prediction. UM has research funding from MRC, CRUK, NIHR, The Eve Appeal. RM has research funding from CRUK, The Eve Appeal and The Barts and the London Charity for population based genetic testing, risk stratification, ovarian cancer prevention and screening. RM declares an honorarium for grant review from Israel National Institute for Health Policy Research.

\section{Ethical Approval}

This commentary is not new research and did not require any ethical approval

\section{Contribution to authorship}

The opinions and conclusions in this commentary are the result of longstanding deliberations between the two authors. RM prepared an initial draft which was critically contributed to by UM. Both approved final version of the manuscript.

\section{Role of Funding Source}

The manuscript is not funded by any charity or grant. 
Table-1: RRSO recommendations

\begin{tabular}{|c|c|c|c|c|}
\hline Clinical Category & Ovarian Cancer Risk & $\begin{array}{l}\text { Recommended age } \\
\text { (years) for RRSO*\# }\end{array}$ & Comments & Reference \\
\hline BRCA1 mutation & $\begin{array}{l}44 \% \text { (range } 40-60 \% \text { ) } * * \\
\text { Risks reported till }<40 \text { range from } 0.6 \% \text { - } \\
3.2 \% \\
\text { Risks between } 40-50 \text { years range from } 6 \% \text { - } \\
22 \%\end{array}$ & $>35-40^{*}$ & $\begin{array}{l}\text { Risk begins to rise at } 35 \text {, becomes more } \\
\text { significant after } 40\end{array}$ & $\begin{array}{l}\text { Kuchenbaecker } \\
2017,{ }^{12} \text { Chen } \\
2007,{ }^{46} \text { Evans } \\
2008^{47} \text { Antoniou } \\
2005^{48} \text { Eastotn } \\
1995^{49} \text { Mavaddat } \\
2013^{50}\end{array}$ \\
\hline BRCA2 mutation & $\begin{array}{l}17 \% \text { (range } 12-30 \% \text { ) } * * \\
\text { Risks reported till }<40 \text { range from } 0-0.7 \% \\
\text { Risks between } 40-50 \text { years range from } 0-4 \%\end{array}$ & $>40-45^{*}$ & $\begin{array}{l}\text { Risk begins to rise at } 40 \text {, becomes more } \\
\text { significant after } 45\end{array}$ & $\begin{array}{l}\text { Kuchenbaecker } \\
2017,{ }^{12} \text { Chen } \\
2007,{ }^{46} \text { Evans } \\
2008^{47}\end{array}$ \\
\hline RAD51C or RAD51D mutation & $11-12 \%$ & $>40-50^{*}$ & $\begin{array}{l}\text { Ovarian cancers have been reproted } \\
\text { between ages } 40-50 \text { in RAD51C/RAD51D } \\
\text { carriers ( } 18 \% \text { cancers in one series were } \\
\text { between } 40-50 \text { years). Overall data are } \\
\text { however limited and precise risk between } \\
40-50 \text { is not well clarified. No cancers as } \\
\text { yet reported at < } 40 \text { in RAD51C/RAD51D } \\
\text { carriers. }\end{array}$ & $\begin{array}{l}\text { Loveday } 2012, \\
{ }^{16} \text { Loveday } 2011^{17}\end{array}$ \\
\hline BRIP1 mutation & $5.80 \%$ & $>50 *$ & $\begin{array}{l}\text { Overall data are limited and precise risk } \\
\text { between } 40-50 \text { is not well clarified. } \\
\text { Cancer has been reported in the } 40-50 \\
\text { age group ( } 7 \% \text { in a small series) but most } \\
\text { occur at }>50 \text { years. }\end{array}$ & Ramus $2015^{18}$ \\
\hline $\mathrm{HBOC}$ or HOC (untested) & $\begin{array}{l}>7-10 \% \text { (depends on } \mathrm{FH} / \text { pattern of } \\
\text { distribution and ages of onset of cancers in } \\
\text { the family) }\end{array}$ & $>40-45^{*}$ & & $\begin{array}{l}\text { Jervis } 2014,{ }^{51} \\
\text { Sutcliffe } 2000,{ }^{52} \\
\text { Jervis } 2015^{11}\end{array}$ \\
\hline
\end{tabular}




\begin{tabular}{|c|c|c|c|c|}
\hline HBOC/HOC BRCA-Negative & $\begin{array}{l}5-11 \% \text { (depends on } \mathrm{FH} / \text { pattern of } \\
\text { distribution and ages of onset of cancers in } \\
\text { the family) }\end{array}$ & $>45^{*}$ & & \\
\hline $\begin{array}{l}\text { HBC only family BRCA- } \\
\text { Negative }\end{array}$ & Population level Risk & RRSO Not recommended & $\begin{array}{l}\text { Women from breast cancer only families } \\
\text { who are BRCA negative on full screen } \\
\text { analysis are not at increased risk of } \\
\text { ovarian cancer. If the family history } \\
\text { changes this risk estimation can change }\end{array}$ & Ingham 2013 \\
\hline $\begin{array}{l}1 \text { FDR with ovarian cancer } \\
\text { (BRCA unknown) }\end{array}$ & $\sim 5-6 \%$ & $>50 *$ & FRR $\sim 3$ (FRR $\sim 3.6$ for serous tumours) & Jervis $2014^{51}$ \\
\hline $\begin{array}{l}2 \text { ovarian cancer case families } \\
\text { (BRCA unknown) }\end{array}$ & $\sim 7-10 \%$ & $>40-45^{*}$ & $\begin{array}{l}\text { FRR } \sim 4 \text { (FRR } 5.1 \text { if exclude early BC } \\
\text { families) }\end{array}$ & Sutcliffe $2000^{52}$ \\
\hline $\begin{array}{l}\geq 3 \text { ovarian cancer case } \\
\text { families (BRCA unknown) }\end{array}$ & 12-14\% & $>40-45^{*}$ & FRR $\sim 7.45$ & Sutcliffe $2000^{52}$ \\
\hline $\begin{array}{l}1 \text { FDR with ovarian cancer } \\
\text { (BRCA Negative) }\end{array}$ & 3.5-4.5\% (5.1\% serous) & $\begin{array}{l}\text { RRSO could be considered } \\
\text { after careful counselling } \\
\text { paritcularly for serous } \\
\text { histology }\left(>50^{*}\right)\end{array}$ & $\begin{array}{l}\text { FRR } \sim 2.25 \text { (FRR is } \sim 2.6 \text { if } \mathrm{OC} \text { is serous } \\
\text { histology) }\end{array}$ & Jervis $2014^{51}$ \\
\hline $\begin{array}{l}2 \text { ovarian cancer case families } \\
\text { (BRCA Negative) }\end{array}$ & $\sim 5-6 \%$ & $>50^{*}$ & FRR 3 & Sutcliffe $2000^{52}$ \\
\hline $\begin{array}{l}\geq 3 \text { ovarian cancer case } \\
\text { families (BRCA Negative) }\end{array}$ & $\sim 11 \%$ & $>40-45^{*}$ & FRR $\sim 7$ & $\begin{array}{l}\text { Sutcliffe } 2000 \text {, } \\
\text { estimated } \\
\end{array}$ \\
\hline $\begin{array}{l}\text { Polygenic (SNP) +/- } \\
\text { Epidemiological based risk }\end{array}$ & Model based estimation $>4-5 \%$ risk & $>50 *$ & & $\begin{array}{l}\text { Jervis } 2015, \\
{ }^{11} \text { Pearce } 2015^{21}\end{array}$ \\
\hline $\begin{array}{l}\text { Lynch Syndrome: MLH1, } \\
\text { MSH2, MSH6 mutations }\end{array}$ & 10\% (6\%-14\%) & $\begin{array}{l}>40^{*} \text { (combined with } \\
\text { hysterectomy for EC risk) }\end{array}$ & & Barrow $2013^{53}$ \\
\hline $\begin{array}{l}\text { Lynch Syndrome: EPCAM } \\
\text { deletion }\end{array}$ & Not high risk for ovarian cancer & RRSO Not recommended & $\begin{array}{l}\text { Ovarian cancer risk is not increased. EC } \\
\text { risk } 16 \% \text { (Hysterectomy may be } \\
\text { considered for increased EC risk) }\end{array}$ & Kempers $2011^{54}$ \\
\hline
\end{tabular}




\begin{tabular}{|c|c|c|c|c|}
\hline $\begin{array}{l}\text { Lynch Syndrome: PMS2 } \\
\text { mutations }\end{array}$ & $\begin{array}{l}\text { Limited publsihed data to accurately } \\
\text { quantify ovarian cancer risk }\end{array}$ & $\begin{array}{l}\text { RRSO not currently } \\
\text { recommended } \\
\text { (Hysterectomy may be } \\
\text { considered for increased } \\
\text { EC risk after } 50 \text { ) }\end{array}$ & $\begin{array}{l}\text { Evidence base for ovarian cancer risk is } \\
\text { limited, though one paper suggests } \\
\text { incresaed OC risk ( } S I R=12 \text { ). RRSO is not } \\
\text { currenlty recommended. This could } \\
\text { change as more evidence accumulates. } \\
\text { EC risk }=12 \% \text { (EC risk between } 40-50 \text { is } \\
<1 \%)\end{array}$ & $\begin{array}{l}\text { Senter } \\
\text { Gastroenterology } \\
2008^{.55} \text { ten } \\
\text { Broeke JCO } \\
2014^{56}\end{array}$ \\
\hline $\begin{array}{l}\text { Additional risks to consider } \\
\text { with Premenopausal } \\
\text { oophorectomy }\end{array}$ & \multicolumn{4}{|c|}{$\begin{array}{l}\text { Subfertility, premature menopause, increased sexual dysfunction; increased risk of osteoporosis; increasaed cardiovascular disease. } \\
\text { Lack of HRT assocaited with increased cardiovascualr mortality; increased risk of neurological sequelae /cognitive dysfunction }\end{array}$} \\
\hline
\end{tabular}

*Some families may have earlier onset ovarian cancers. RRSO may be undertaken up to 5 years before the earliest age of onset of ovarian cancer in the family.

**higher end estimates are reported from estimates ascertained through high risk families attending cancer genetics clinics. Lower end estimates are from studies correcting for ascertainment.

\#Timing of RRSO needs to be decided after thorough counselling of pros and cons including surgical complications and after taking into account patients wishes, including fertility and premature menopause issues along with HRT use (premenopausal women)."

FDR- First degree relative; FRR - familial relative risk; EC- endometrial cancer; HBC- high risk breast cancer only family; HBOC - high risk breast \& ovarian cancer family; HOC - high risk ovarian cancer only family; RRSO- risk reducing salpingo-oophorectomy 


\section{References}

[1] International Agency for Research on Cancer. GLOBOCAN 2012: Estimated Cancer Incidence, Mortality and Prevalence Worldwide in 2012. Online Analysis > Prediction. Lyon, France: IARC (International Agency for Research on Cancer) 2016:http://globocan.iarc.fr/Pages/burden sel.aspx. [2] CRUK. Ovarian cancer survival statistics. Ovarian cancer survival trends over time, 19712011. London, UK: Cancer Research UK 2015:http://www.cancerresearchuk.org/healthprofessional/cancer-statistics/statistics-by-cancer-type/ovarian-cancer/survival\#heading-Two. [3] Jacobs IJ, Menon U, Ryan A et al. Ovarian cancer screening and mortality in the UK Collaborative Trial of Ovarian Cancer Screening (UKCTOCS): a randomised controlled trial. Lancet. 2015.

[4] Rosenthal AN, Fraser LS, Philpott S et al. Evidence of Stage Shift in Women Diagnosed With Ovarian Cancer During Phase II of the United Kingdom Familial Ovarian Cancer Screening Study. J Clin Oncol. 2017: JCO2016699330.

[5] Menon U, Skates S, McGuire A et al. Long term impact of screening on ovarian cancer mortality in the UK Collaborative Trial of Ovarian Cancer Screening (UKCTOCS). Southampton, United Kingdom: National Instittue for Health Researcch (NIHR) 2017:https://www.journalslibrary.nihr.ac.uk/programmes/hta/164601/\#/.

[6] Independent Cancer Task Force. Achieving world-class cancer outcomes: a strategy for England 2015-2020. London, UK: Cancer Research UK

2015:http://www.cancerresearchuk.org/sites/default/files/achieving worldclass cancer outcomes - a strategy for england 2015-20.pdf.

[7] The White House. Remarks by the President on Precision Medicine. Office of the Press Secretary, The White House, USA 2015:https://www.whitehouse.gov/the-pressoffice/2015/01/30/remarks-president-precision-medicine.

[8] CRUK. Ovarian Cancer, Key Stats. Cancer Statistics. Nov 2014 ed. CRUK: Cancer Research UK 2014:1-2, http://publications.cancerresearchuk.org/downloads/Product/CS KF OVARY.pdf

[9] SEER. SEER Cancer Statistics Factsheets: Ovary Cancer. Bethesda, MD, USA: National Cancer Institute. 2014:http://seer.cancer.gov/statfacts/html/ovary.html (accessed 10/03/2015).

[10] Chen EY, Mehra K, Mehrad M et al. Secretory cell outgrowth, PAX2 and serous carcinogenesis in the Fallopian tube. J Pathol. 2010;222: 110-6.

[11] Jervis $\mathrm{S}$, Song $\mathrm{H}$, Lee $\mathrm{A}$ et al. A risk prediction algorithm for ovarian cancer incorporating BRCA1, BRCA2, common alleles and other familial effects. J Med Genet. 2015.

[12] Kuchenbaecker KB, Hopper JL, Barnes DR et al. Risks of Breast, Ovarian, and Contralateral Breast Cancer for BRCA1 and BRCA2 Mutation Carriers. JAMA. 2017;317: 2402-16.

[13] Manchanda $R$, Abdelraheim A, Johnson $M$ et al. Outcome of risk-reducing salpingooophorectomy in BRCA carriers and women of unknown mutation status. Bjog. 2011;118: 814-24.

[14] Rosenthal AN, Fraser L, Manchanda R et al. Results of annual screening in phase I of the United Kingdom familial ovarian cancer screening study highlight the need for strict adherence to screening schedule. J Clin Oncol. 2013;31: 49-57.

[15] Manchanda R, Burnell M, Abdelraheim A et al. Factors influencing uptake and timing of risk reducing salpingo-oophorectomy in women at risk of familial ovarian cancer: a competing risk time to event analysis. Bjog. 2012.

[16] Loveday C, Turnbull C, Ruark E et al. Germline RAD51C mutations confer susceptibility to ovarian cancer. Nat Genet. 2012;44: 475-6; author reply 6.

[17] Loveday C, Turnbull C, Ramsay E et al. Germline mutations in RAD51D confer susceptibility to ovarian cancer. Nat Genet. 2011;43: 879-82.

[18] Ramus SJ, Song H, Dicks E et al. Germline Mutations in the BRIP1, BARD1, PALB2, and NBN Genes in Women With Ovarian Cancer. J Natl Cancer Inst. 2015;107. 
[19] Kuchenbaecker KB, Ramus SJ, Tyrer J et al. Identification of six new susceptibility loci for invasive epithelial ovarian cancer. Nat Genet. 2015;47: 164-71.

[20] Phelan CM, Kuchenbaecker KB, Tyrer JP et al. Identification of 12 new susceptibility loci for different histotypes of epithelial ovarian cancer. Nat Genet. 2017.

[21] Pearce CL, Stram DO, Ness RB et al. Population distribution of lifetime risk of ovarian cancer in the United States. Cancer Epidemiol Biomarkers Prev. 2015;24: 671-6.

[22] Clyde MA, Palmieri Weber R, Iversen ES et al. Risk Prediction for Epithelial Ovarian Cancer in 11 United States-Based Case-Control Studies: Incorporation of Epidemiologic Risk Factors and 17 Confirmed Genetic Loci. Am J Epidemiol. 2016;184: 579-89.

[23] PROMISE FS. Predicting risk of ovarian malignancy improved screening and early detection: Feasibility study Biomed Central 2017:DOI 10.1186/ISRCTN54246466 http://www.isrctn.com/ISRCTN.

[24] Madalinska JB, Hollenstein J, Bleiker E et al. Quality-of-life effects of prophylactic salpingooophorectomy versus gynecologic screening among women at increased risk of hereditary ovarian cancer. J Clin Oncol. 2005;23: 6890-8.

[25] Rebbeck TR, Kauff ND, Domchek SM. Meta-analysis of risk reduction estimates associated with risk-reducing salpingo-oophorectomy in BRCA1 or BRCA2 mutation carriers. J Natl Cancer Inst. 2009;101: 80-7.

[26] Domchek SM, Friebel TM, Singer CF et al. Association of risk-reducing surgery in BRCA1 or BRCA2 mutation carriers with cancer risk and mortality. Jama. 2010;304: 967-75.

[27] Parker WH, Feskanich D, Broder MS et al. Long-term mortality associated with oophorectomy compared with ovarian conservation in the nurses' health study. Obstet Gynecol. 2013;121: 709-16.

[28] Anderson K, Jacobson JS, Heitjan DF et al. Cost-effectiveness of preventive strategies for women with a BRCA1 or a BRCA2 mutation. Ann Intern Med. 2006;144: 397-406.

[29] Manchanda R, Legood R, Antoniou AC et al. Specifying the ovarian cancer risk threshold of 'premenopausal risk-reducing salpingo-oophorectomy' for ovarian cancer prevention: a costeffectiveness analysis. J Med Genet. 2016;53: 591-9.

[30] Manchanda R, Legood R, Pearce L, Menon U. Defining the risk threshold for risk reducing salpingo-oophorectomy for ovarian cancer prevention in low risk postmenopausal women. Gynecol Oncol. 2015.

[31] NICE. Guide to the methods of technology appraisal. N1618 ed. London: National Institute for Health and Clinical Excellence (NICE) 2008.

[32] van den Akker-van Marle ME, van Ballegooijen M, van Oortmarssen GJ et al. Costeffectiveness of cervical cancer screening: comparison of screening policies. J Nat/ Cancer Inst. 2002;94: 193-204.

[33] Rebbeck TR, Friebel T, Wagner T et al. Effect of short-term hormone replacement therapy on breast cancer risk reduction after bilateral prophylactic oophorectomy in BRCA1 and BRCA2 mutation carriers: the PROSE Study Group. J Clin Oncol. 2005;23: 7804-10.

[34] Falconer $\mathrm{H}$, Yin L, Gronberg H, Altman D. Ovarian cancer risk after salpingectomy: a nationwide population-based study. J Nat/ Cancer Inst. 2015;107.

[35] Madsen C, Baandrup L, Dehlendorff C, Kjaer SK. Tubal ligation and salpingectomy and the risk of epithelial ovarian cancer and borderline ovarian tumors: a nationwide case-control study. Acta Obstet Gynecol Scand. 2015;94: 86-94.

[36] Darelius A, Lycke M, Kindblom JM et al. Efficacy of salpingectomy at hysterectomy to reduce the risk of epithelial ovarian cancer: a systematic review. BJOG. 2017.

[37] Gan C, Chenoy R, Chandrasekaran D et al. Persistence of fimbrial tissue on the ovarian surface after salpingectomy. Am J Obstet Gynecol. 2017.

[38] Powell CB. Risk reducing salpingo-oophorectomy for BRCA mutation carriers: twenty years later. Gynecol Oncol. 2014;132: 261-3. 
[39] Eckert MA, Pan S, Hernandez KM et al. Genomics of Ovarian Cancer Progression Reveals Diverse Metastatic Trajectories Including Intraepithelial Metastasis to the Fallopian Tube. Cancer Discov. 2016;6: 1342-51.

[40] Meserve EE, Brouwer J, Crum CP. Serous tubal intraepithelial neoplasia: the concept and its application. Mod Pathol. 2017.

[41] Harlow SD, Gass M, Hall JE et al. Executive summary of the Stages of Reproductive Aging Workshop + 10: addressing the unfinished agenda of staging reproductive aging. Menopause. 2012;19: 387-95.

[42] Kwon JS, Tinker A, Pansegrau G et al. Prophylactic salpingectomy and delayed oophorectomy as an alternative for BRCA mutation carriers. Obstet Gynecol. 2013;121: 14-24.

[43] Harmsen MG, Arts-de Jong $M$, Hoogerbrugge $N$ et al. Early salpingectomy (TUbectomy) with delayed oophorectomy to improve quality of life as alternative for risk-reducing salpingooophorectomy in BRCA1/2 mutation carriers (TUBA study): a prospective non-randomised multicentre study. BMC Cancer. 2015;15: 593.

[44] Leblanc E, Narducci F, Farre I et al. Radical fimbriectomy: a reasonable temporary riskreducing surgery for selected women with a germ line mutation of BRCA 1 or 2 genes? Rationale and preliminary development. Gynecol Oncol. 2011;121: 472-6.

[45] Chandrasekaran D, Menon U, Evans G et al. Risk reducing salpingectomy and delayed oophorectomy in high risk women: views of cancer geneticists, genetic counsellors and gynaecological oncologists in the UK. Fam Cancer. 2015;14: 521-30.

[46] Chen S, Parmigiani G. Meta-analysis of BRCA1 and BRCA2 penetrance. J Clin Oncol. 2007;25: 1329-33.

[47] Evans DG, Shenton A, Woodward E et al. Penetrance estimates for BRCA1 and BRCA2 based on genetic testing in a Clinical Cancer Genetics service setting: risks of breast/ovarian cancer quoted should reflect the cancer burden in the family. BMC Cancer. 2008;8: 155.

[48] Antoniou AC, Pharoah PD, Narod S et al. Breast and ovarian cancer risks to carriers of the BRCA1 5382insC and 185delAG and BRCA2 6174delT mutations: a combined analysis of 22 population based studies. J Med Genet. 2005;42: 602-3.

[49] Easton DF, Ford D, Bishop DT. Breast and ovarian cancer incidence in BRCA1-mutation carriers. Breast Cancer Linkage Consortium. Am J Hum Genet. 1995;56: 265-71.

[50] Mavaddat N, Peock S, Frost D et al. Cancer risks for BRCA1 and BRCA2 mutation carriers: results from prospective analysis of EMBRACE. J Natl Cancer Inst. 2013;105: 812-22.

[51] Jervis $\mathrm{S}$, Song $\mathrm{H}$, Lee $\mathrm{A}$ et al. Ovarian cancer familial relative risks by tumour subtypes and by known ovarian cancer genetic susceptibility variants. J Med Genet. 2014;51: 108-13.

[52] Sutcliffe S, Pharoah PD, Easton DF, Ponder BA. Ovarian and breast cancer risks to women in families with two or more cases of ovarian cancer. Int J Cancer. 2000;87: 110-7.

[53] Barrow E, Hill J, Evans DG. Cancer risk in Lynch Syndrome. Fam Cancer. 2013;12: 229-40.

[54] Kempers MJ, Kuiper RP, Ockeloen CW et al. Risk of colorectal and endometrial cancers in EPCAM deletion-positive Lynch syndrome: a cohort study. Lancet Oncol. 2011;12: 49-55.

[55] Senter L, Clendenning M, Sotamaa K et al. The clinical phenotype of Lynch syndrome due to germ-line PMS2 mutations. Gastroenterology. 2008;135: 419-28.

[56] ten Broeke SW, Brohet RM, Tops CM et al. Lynch syndrome caused by germline PMS2 mutations: delineating the cancer risk. J Clin Oncol. 2015;33: 319-25. 